\title{
Recluta masiva de emigrantes andaluces y su inserción social en Argentina (siglo XIX). Nuevas notas para su estudio
}

\author{
Francisco Contreras Pérez
}

Becario de investigación. Universidad de Sevilla

Se estudia el papel de la Agencia de Emigración Señores Acebal Díaz y Cía., y de la naviera Italo-Argentina, en la recluta masiva de emigrantes andaluces llevaba a cabo en 1889. Supuso la definición de una nueva etapa (no lineal) en el trasvase poblacional entre Andalucía y América: la emigración en masa. A continuación, el estudio se completa con una aproximación al proceso inmediato de inserción de este contingente migratorio en el mercado de trabajo argentino.

A fines del siglo XIX, la República Argentina estaba en un proceso de expansión agropecuaria, dentro del papel como exportador de productos primarios que tenía asumido en el sistema económico mundial. El país necesitaba imperiosamente importar trabajadores extranjeros para poner en explotación extensos y fértiles territorios.

En 1889, el Gobierno argentino, con el fin de promover la inmigración masiva, repartió 100.000 pasajes subsidiados (cuyo importe era adelantado por el Estado) en Europa. Uno de los proyectos se concretó en Andalucía, especialmente en las provincias de Granada, Málaga y Cádiz. Entre otros, el sector vitícola, fundamental para la economía de estas provincias, pasaba por una profunda crisis de producción (a causa de la filoxera) y comercial (por los cambios registrados en los mercados tradicionales de los vinos andaluces).

En torno a veinte mil andaluces emigraron aquel año a Argentina. Los pasajes subvencionados no sólo explican la dimensión cuantitativa de este contingente, sino que también condicionan la naturaleza del mismo y, en cierto sentido, su inserción en la sociedad argentina.

\section{Una empresa argentina para la emigración andaluza}

En 1853, la proclamada Carta Magna de la República Argentina daba la máxima expresión jurídica a la idea alberdiana: "Gobernar es po- 
blar". ${ }^{1} \mathrm{Su}$ artículo 25 preceptuaba que “el Gobierno Federal fomentará la inmigración europea...”. ${ }^{2}$ Con este fin, el 19 de octubre de 1876 se aprobó la Ley de Inmigración y Colonización argentina, modelo de leyes similares en otros países sudamericanos. ${ }^{3}$ Además de crear una estructura de acogida de los inmigrantes (los Hoteles de Inmigrantes), en su artículo 3 . $^{\circ}$ se facultaba al nuevo Departamento Central de Inmigración para “... intervenir en los contratos de transporte $\mathrm{y}$, en algunos casos, pagar sus pasajes". ${ }^{4} \mathrm{El}$ Gobierno argentino, pensando en un principio en los noreuropeos, esperaba que el extranjero cumpliera, en la modernización del país, un papel primordial por su trabajo, su experiencia, sus conocimientos agropecuarios y por el capital que pudieran llevar consigo al instalarse en América. El viejo edificio colonial debía ser derruido. ${ }^{5}$ Pero la orientación de los noreuropeos a Estados Unidos hizo fracasar estos primeros intentos. "A posteriori, y un tanto a regañadientes", se descubrió, para apreciarla, la afinidad étnico-cultural de los emigrantes del sur de Europa y la sociedad argentina.

En 1889, y tras una polémica social y política sobre la conveniencia de subvencionar la inmigración, el Gobierno argentino envió 100.000 pasajes subsidiados a Europa. Unos cincuenta y dos mil de estos pasajes llegaron a España donde, según parece, financiaron al $75 \%$ de la emigración de ese año. ${ }^{6}$ La emigración española, y especialmente la andaluza, alcanzaron entonces el nivel más alto durante el siglo XIX, no superado hasta 1912.

A pesar de haber sido aceptada "por necesidad" en Argentina la inmigración de europeos del sur hacia la década de los 80, los andaluces seguían sufriendo en general una extendida "mala fama" como trabajadores, y quizás se les relacionaba en exceso con la denostada sociedad colonial. En este sentido, un articulista del Diario de Buenos Aires ofrecía la particular imagen de una Andalucía en claroscuro:

"Fuera de los olivares de Granada y de los viñedos de Jerez y de Málaga; en el resto de Andalucía no se ve nada que atestigüe la laboriosidad de sus pobladores".

1 Sánchez Albornoz, N.: La población de América Latina, desde los tiempos precolombinos al año 2.000, Madrid, 1973, págs. 169-209.

2 Ibídem.

3 La Ley de Colonización Agrícola de 1880 y Ley de Inmigración de 1890, en Uruguay, y la Ley de Inmigración y Colonización de 1881 en Paraguay. VV. AA.: Historia General de la emigración española a Iberoamérica, Madrid, 1992, pág. 264.

4 Ley de Inmigración y Colonización, art. 3. ${ }^{\circ}$ citado. Ibídem.

5 Azcona, J.M.: "El poder de los ganchos", ponencia presentada en el IV Encuentro de Americanistas, Oviedo, 1994 (copia de la ponencia).

6 VV. AA.: Historia General..., pág. 231.

7 Citado en Diario de Cádiz, Cádiz, 1 de agosto de 1889, pág. 1. 
Los cincuenta y dos mil pasajes destinados a España tenían un valor total aproximado de 3.120.000 pesos argentinos de la época. ${ }^{8}$ Este tipo de gastos estaba previsto en el capítulo X , "Los fondos de Inmigración”, de la Ley de Inmigración Argentina. Estos fondos estaban compuestos por recursos provenientes de las cantidades que la Ley General del Presupuesto destinara anualmente a este objetivo, de las cantidades que entregasen la Oficina de Tierras y Colonias, del producto de las multas fijadas por la Ley de Inmigración y de las cuotas pagadas por los inmigrantes. La administración de ese fondo de dinero público correspondía al Departamento Central de Inmigración, quien lo podría destinar:

"1. $\mathrm{Al}$ adelanto o pago de pasajes para los inmigrantes en los casos determinados por la Ley.

2. ${ }^{\circ} \quad$ Al servicio de los contratos que se hicieren con los buques conductores de inmigrantes para el transporte de éstos a la República ...". ${ }^{\circ}$

A nadie se le podía escapar entonces que prometía ser un buen negocio, pues en eso consistía para algunos la emigración. Así lo entendieron los Señores Acebal Díaz y Cía., agencia de inmigración con sede en Buenos Aires, que ofrecieron al Departamento de Inmigración argentino conducir, en el plazo de un año, 30.000 emigrantes españoles y portugueses en vapores especiales a Argentina. La propuesta de la Agencia Señores Acebal Díaz y Cía. obtuvo finalmente la concesión oficial de su gobierno, según las siguientes bases:

"1. ${ }^{\text {a }}$ El número de inmigrantes que deberán traer, será de treinta mil, como mínimum, de las provincias españolas y Portugal en el término de un año, a contar desde el $1 .^{\circ}$ de Abril próximo.-

2. ${ }^{a} \quad$ Los inmigrantes serán conducidos en vapores especiales que no sean de los que hacen actualmente idéntico servicio, no pudiendo en ningún caso poder traer en éstos, sino por causas excepcionales, un número mayor de cuatro mil inmigrantes, durante el tiempo que dure esta concesión.-

3. ${ }^{a} \quad$ Los vapores que conducen los inmigrantes deberán llevar por mitad, por lo menos, bandera argentina.-

4. ${ }^{a} \quad$ Los inmigrantes serán industriales y agricultores, y solicitarán por escrito el pasaje subsidiario ante los cónsules y oficinas de información, en su respectivo

8 Las principales sumas aplicadas por el Tesoro argentino para beneficio de la inmigración en 1889 fueron (en pesos moneda nacional): pasajes subsidiados, 5.507.704; construcción de hoteles, 750.000; Oficinas de Información, 300.000. $2^{\circ}$ Censo Nacional de la República Argentina. Mayo de 1895, Buenos Aires, 1898, pág. 649.

9 Citado en el Boletín del Consejo Superior de Emigración, Madrid, 1911, T. III, núm. 34, págs. 516-517. 
caso, que los condujeran, comprobando que los solicitantes se encuentran en todas las condiciones de la ley de inmigración, y entregando al interesado un boleto de permiso para poder embarcarse.-

5. ${ }^{\text {a }}$ Los cónsules y oficinas de Información remitirán al Departamento General de Inmigración la lista de los pasajes subsidiados concedidos, y conducidos por cada vapor.-

6..$^{\circ} \quad$ Los vapores destinados a este servicio, observarán estrictamente la ley de inmigración.-

7. El Departamento General de Inmigración abonará sesenta pesos, moneda nacional curso legal, por cada pasaje, de acuerdo con la ley núm. 2252 de 3 de Noviembre de 1887, y decretos reglamentarios, una vez firmadas las letras respectivas por los inmigrantes.-

8. $\quad$ Los Sres. Acebal Díaz y Cía., no podrán cobrar a los inmigrantes ninguna suma por comisión, ni bajo otra forma, de modo que sólo tengan que abonar el pasaje subsidiario, con arreglo a la ley.-

9. $\quad$ El 5 por 100 del valor que representan los pasajes subsidiarios, será detenido a la orden del Departamento General de Inmigración, como garantía del cumplimiento a esta propuesta.-

10. ${ }^{a}$ Comuníquese a las legaciones argentinas en España y Portugal, comuníquese a los interesados, y pase al Departamento General de Inmigración a sus efectos.Juárez Celman.- N. Quirno Costa.- E. Wilde.- E. W. Pacheco Ricardo.- Filemón Posse." ${ }^{\prime 10}$

El volumen del negocio contratado por los Señores Acebal Díaz y Cía. se elevaba, de acuerdo con la base $7 .^{\mathrm{a}}$ del contrato, a 1.800 .000 pesos argentinos. De los 30.000 pasajes, se destinarían al parecer 24.000 a la recluta de "industriales y agricultores" en las provincias españolas, según cálculos de La Gaceta Industrial del Ministerio de Fomento español. ${ }^{11}$ En todo caso, pudieron dirigirse los 30.000 a España, en tanto que la diferencia entre un emigrante portugués y otro español posiblemente no era más que una cuestión de matiz para alguien que veía en la emigración masiva sólo un negocio. Así, consta en la Gaceta Agrícola del mencionado Ministerio un comentario al respecto, indicando la nueva corriente de emigración hacia América desde Andalucía:

"Recientemente, una Compañía titulada Italo-Argentina se ha comprometido con el Gobierno de aquella República a llevar 30.000 emigrantes españoles". ${ }^{12}$

10 Diario de Cádiz, Cádiz, 27 de marzo de 1889. Estas bases fueron remitidas al rotativo gaditano por "un apreciable amigo y paisano nuestro" desde Buenos Aires.

11 Citado en el rotativo La Andalucía, Sevilla, 25 de abril de 1889.

12 Gaceta Agrícola, Ministerio de Fomento, Madrid, 1889, t.III, pág. 442. 
Estos 30.000 pasajes subsidiarios representaban el 58\% de los 52.000 pasajes que, según algunos autores, llegaron a España. Esto corrobora la magnitud de esta empresa.

Para llevarla a cabo, los Señores Acebal Díaz y Cía. necesitaban naturalmente una flota de buques. Estos deberían estar dotados de motores a vapor que permitieran hacer varios viajes en un año, y sobre todo tener la capacidad suficiente para amortizar los gastos de transporte. Ahora bien, según las bases $2^{\mathrm{a}}$ y $3^{\mathrm{a}}$ del contrato, y dado que se manejaban fondos públicos argentinos, se exigía que esa flota de vapores no perteneciera a las líneas regulares de transporte (en su mayoría, europeas), y debería estar compuesta, al menos en su mitad, por buques bajo pabellón argentino. El negocio era tan voluminoso que los Acebal, Díaz y Cía. decidieron contar con una línea de vapores ad hoc, que se anunciaría como: "La Nueva Línea de Vapores Italo-Argentina."

Para su creación, habían contactado con la Casa armadora de Luigi Solari, con sede en Génova. Esta naviera se dedicaba hasta entonces al transporte de mercancías por el Atlántico, y era propietaria de una flota de buques de hierro de la clase cargo-boat, como se les denominaba, o sea cargueros. La Casa Luigi Solari firmó el contrato con los Sres. Acebal y Díaz, y desvió para este servicio seis buques que estarían inscritos respectivamente como: "San Martino", "Fanfulla", "Solferino", "Progreso", "Argentino" y "Pacífico". Acordaron que los tres primeros llevarían bandera italiana y los otros tres navegarían bajo pabellón argentino. ${ }^{13}$

La Comisión General de Emigración argentina exigía que los buques reuniesen las condiciones de habitabilidad impuestas por la Ley de Inmigración de la República, que daba competencias a esta autoridad de inmigración para inspeccionar los buques conductores de inmigrantes en los puntos referentes al alojamiento, alimentación, comodidades, régimen higiénico y seguridad. ${ }^{14}$ Así pues, se hizo habilitar los seis cargueros para el transporte de personas. En general, los buques, aparejados de bergantín-goleta y con 1.800 toneladas de registro cada uno, fueron dotados con unas 1.140 literas en sus dos entrepuentes (proa y popa, separando mujeres de hombres), cada una de ellas con un colchón y una manta; siempre se superó esta capacidad en unos cientos - a causa de los niños, no contabilizados como pasajeros-, si bien nunca se llegó a la exagerada cifra de 4.000. Llevaban también dos departa-

13 El Guadalete, Jerez de la Frontera, 1 de mayo de 1889.

14 Citado en el Boletín del Consejo Superior ..., pág. 512. Las condiciones de habitabilidad de los buques se recogían en la base $6 .^{\text {a }}$ del contrato con la Agencia. En el capítulo $1 .^{\circ}$, art. 30 de la Ley de Inmigración se hacía competente a la Comisión General de Inmigración en las tareas de supervisión. 
mentos para enfermería con 14 literas cada uno, y los víveres "necesarios" (entre éstos, animales vivos para tener carne y leche frescas durante la travesía). Los vapores también admitían carga. Además de sus casi cuarenta y cinco tripulantes, en cada barco viajarían un médico y un agente de los Señores Acebal Díaz y Cía. asistiendo a los emigrantes.

Se coordinarían los viajes de los seis vapores para que, durante el año que duraba la concesión, saliesen sucesivamente de puerto cada 15 días. Los vapores embarcarían emigrantes en Barcelona, Valencia, Málaga, Gibraltar y Cádiz, aunque no necesariamente en todos estos puertos en un solo viaje (algunos pusieron rumbo a América desde Málaga o Gibraltar). El que abrió el servicio fue el "San Martino" que, procedente de Málaga (y quizá de Gibraltar), fondeó en Cádiz el 29 de abril para dirigirse días después a Buenos Aires. El calendario de salidas anunciadas en ocasiones se modificó por accidentes fortuitos, como el incendio del vapor "Pacífico" en Málaga, que originó numerosos trastornos y penurias a los emigrantes que esperaban tanto en este puerto como en el de Gibraltar. ${ }^{15}$

De esta manera empezaba a funcionar la "Italo-Argentina", donde tenían intereses comunes los argentinos Señores Acebal Díaz y Cía. y la Casa italiana Luigi Solari. Se había hecho una inversión inicial, tanto por la habilitación de los cargueros como por lo dejado de ganar mientras estuvieron en dique seco. El beneficio dependería obviamente del mayor número de emigrantes que consiguieran transportar a Argentina durante el año estipulado en el contrato.

La empresa de emigración ya disponía del medio de transporte según las bases del contrato con el Estado argentino. Encontrar miles de personas dispuestas a emigrar con pasaje subsidiado, ansiosas de hacer las Américas y esperando en los puertos el arribo de los buques, quizás fue lo menos difícil. En todo caso, esto dependía del "personal de tierra" de la empresa: agentes y ganchos.

El éxito de la nueva empresa de transporte marítimo "Italo-Argentina" dependió en gran medida de la labor de sus representantes en los puertos. La tarea de los consignatarios y de los ganchos fue básica para difundir y facilitar la idea de emigrar, aprovechándose así de una situación propicia a la emigración. En estos términos, reflejaba un diario jerezano la actitud observada por los agentes:

15 En Málaga el consignatario de la compañía, don Pedro Gómez Gómez, decidió repartir una peseta por emigrante y día de espera. En Gibraltar los emigrantes andaluces tuvieron que recurrir a la caridad para subsistir, una vez agotados los escasos recursos que llevaban. 
"No es sólo la penuria del país ni la miseria de algunas comarcas lo que impulsa a muchas familias que abandonan el suelo español para trasladarse a las repúblicas sudamericanas ... Pues si a esto se unen los pomposos anuncios que diariamente publican las Compañías de vapores trasatlánticos, celebrando las excelencias de aquellas Repúblicas y haciendo concebir las más risueñas esperanzas a los emigrantes ... nada es más natural que muchos infelices, creyendo de buena fe las falaces ilusiones que han hecho forjar en su imaginación los activos propagandistas del embarque, se procuren por cualquier medio la suma necesaria para ser conducidos a donde tanto bien les ofrecen, sin otro sacrificio ni contingencia que el de un viaje por mar, de veinte o treinta días, que para muchos serán de fiesta y regocijo". ${ }^{16}$

En esta situación, y si además los pasajes estaban subsidiados como en 1889, no había necesidad de efectuar una propaganda muy activa. Los agentes se limitaban a anunciar en ciertas localidades costeras, y del interior, las fechas de salida de los vapores. Este medio fue suficiente para conseguir millares de pasajeros que afluyeron al puerto de embarque. ${ }^{17}$

Los agentes de las capitales solían viajar a los pueblos del entorno, donde anunciaban a viva voz las "fabulosas oportunidades" que ofrecía América y la gratuidad del pasaje. Además de señalar a la crisis económica como la principal causa del éxodo, la opinión pública de entonces no desconocía el decisivo papel de estos "ganchos reclutadores" como último eslabón en el proceso de toma de decisión de emigrar. Si los candidatos a emigrar eran numerosos, como ocurría cuando había pasajes subsidiados, los agentes solían elaborar listas de emigrantes en el pueblo visitado. A partir de estas listas, iban formando expediciones sucesivas hacia los puertos, según las fechas previstas de llegada de los vapores.

Otro medio de propaganda consistía en anuncios de prensa, como los aparecidos a lo largo de casi todo el año en el más importante periódico granadino, El Defensor de Granada:

"PASAJES SUBSIDIARIOS para la REPÚBLICA ARGENTINA (BUENOS AIRES).- Los que deseen, recibirán gratuitamente toda clase de noticias dirigiéndose al Director de la Oficina oficial de Información en Madrid, calle del Desengaño, núm. 27, segundo izquierda. Para referencias en esta localidad acudir al señor don T. J. BARTRON, calle del Toril, núms. 15 y 17 ". ${ }^{18}$

16 El Guadalete, Jerez de la Frontera, 17 de octubre de 1888.

17 Así se decía en un despacho (6 de octubre de 1889) del cónsul francés en Cádiz, citado por Bernal, A. M.: "La emigración andaluza", en Sánchez Albornoz, N.: Españoles hacia América. La emigración en masa, 1880-1930, Madrid, 1988.

18 El Defensor de Granada, Granada, varios núms. de 1889. Aparecen normalmente en la última página, dedicada a anuncios . 
Al parecer, también se publicaron en la Unión Mercantil de Málaga. No obstante, en periódicos tan importantes como La Andalucía de Sevilla, el Diario de Cádiz y El Guadalete de Jerez no hemos encontrado anuncios de pasajes subsidiados para Argentina, a pesar de contener ofertas de varias compañías navieras y ser Cádiz una de las provincias más afectadas por esta recluta. Curiosamente, en los dos diarios gaditanos mencionados aparecen frecuentes anuncios de la "Nueva Línea Italo-Argentina", pero sólo haciendo constar que los buques también pueden llevar carga (esos anuncios se dirigían, pues, a comerciantes e industriales). Estas ausencias nos hacen suponer que las tareas de propaganda y recluta de emigrantes se realizaron fundamentalmente de forma oral (recordemos los altos índices de analfabetismo en las provincias andaluzas), a cargo de ganchos locales dependientes no de los consignatarios portuarios, sino de la Oficina de los Señores Acebal, Díaz y Cía. en Madrid.

Los consignatarios de la "Italo-Argentina" estaban radicados en los tres principales puertos andaluces en el tráfico de pasajeros con América (Almería no lo sería hasta el siglo XX): Málaga: don Pedro Gómez Gómez; Gibraltar: señores M. H. Blaud y Compañía; Cádiz: don Eduardo de Guernica, c/ Doblones, n. ${ }^{\circ} 20$.

Estos señores posiblemente habían trabajado con la Casa de Luigi Solari en el comercio de vinos de Andalucía a Argentina (comercio que ahora estaba en crisis). Los tres consignatarios pasaron al servicio de la nueva compañía de emigración. La "Italo-Argentina" contaba con otros consignatarios en puertos del Levante, pero los andaluces fueron, con diferencia, los que más emigrantes embarcaron en los buques de la empresa. Así se desprende de la composición del pasaje de tres de los vapores. De acuerdo con estos datos parciales, los consignatarios andaluces y el gibraltareño administraron el 91,32\% del pasaje de la "Italo-Argentina". En volumen de negocio, esto representó para la compañía, en el caso de haberse completado los 24.000 pasajes subsidiados, un valor de 1.315 .000 pesos a pagar por el Estado argentino. Y, entre los andaluces, el consignatario malagueño don Pedro Gómez Gómez estuvo a la cabeza (40\% del pasaje de la "Italo-Argentina").

En la Málaga de los 80, don Pedro Gómez Gómez era el prototipo social del republicanismo centrista. En 1885 figuraba en una guía de la ciudad como "comerciante capitalista", fabricante de aguardientes, especulador en frutos del país, consignatario de buques de vela y vapor y exportador de vinos. Cónsul de Bolivia en Málaga, sus relaciones con las 
repúblicas sudamericanas fueron la causa de un activo comercio entre dichos lugares y Málaga, hasta el punto de conseguir que viniesen a su ciudad varias importantes líneas de vapores que con anterioridad nunca habían hecho escala en este puerto. ${ }^{19}$

Aunque a menor nivel, Pedro Gómez Gómez había intervenido en el negocio de la emigración en 1886. Ese año asesoró al director del Ingenio Azucarero San Felipe de Tucumán, de visita en Málaga, para la recluta de 27 obreros. $^{20}$ Aún más significativo es que el hermano menor de Pedro Gómez Gómez, Salvador, "opulento financiero español residente en Buenos Aires", ${ }^{21}$ estaba al frente del Banco Nacional. ${ }^{22}$

Así pues, don Pedro Gómez Gómez poseía los contactos necesarios para estimular una emigración en masa, que le prometía un buen negocio como consignatario. Conocía la deprimida situación de las familias menesterosas en los pagos andaluces, prestas a emigrar ante la menor oportunidad. A su vez, poseía poderosas influencias en el mundo mercantil y financiero argentino, interesado en subvencionar el transporte de familias obreras para la puesta en explotación de nuevos territorios. ${ }^{23}$

\section{El papel de la empresa en el contexto emigratorio andaluz}

\section{Un aluvión emigratorio}

La Andalucía tuvo constancia inmediata de la importancia del paso dado por el Gobierno argentino a la hora de contratar con los Acebal Díaz y Cía. la importación de 30.000 obreros españoles. En el mes que entraba en vigor el contrato, el diario sevillano dedicaba un alarmado editorial al asunto, en el que se decía:

19 Arcas Cubero, F.: El republicanismo malagueño durante la Restauración (1875-1923), Córdoba, 1985.

20 Mateo Avilés, E.: La emigración andaluza a América (1850-1930), Málaga, 1993, pág. 99.

21 La Andalucía, Sevilla, 1 de septiembre de 1889, pág. 1.

22 Mateo Avilés, E.: La emigración andaluza..., págs. 295-297.

23 El hijo de Pedro Gómez Gómez, Pedro Gómez Cháix, sucedería a su padre en el negocio de la emigración a principios del siglo XX, como consignatario de la naviera francesa "Société Générale de Transports Maritimes à Vapeur". Esta naviera creó una filial, la "France-Amérique", para el transporte desde Gibraltar de expediciones de emigrantes con pasajes subsidiados por Brasil, actividad prohibida por el gobierno español. Despachos del Cónsul de España en Gibraltar, verano de 1909, archivados en el Archivo General de la Administración (AGA), Asuntos Exteriores (AE), 1700. 
"Y lo que más apoca el ánimo, en esta ocasión, es que esta emigración reviste los caracteres de una leva extraordinaria, distinta de la que se viene efectuando un día tras otro en nuestras costas del Norte y Levante, como queda justificado leyendo dicho decreto [...][Se trata en esta ocasión] de una emigración que amenaza acabar con todas las fuerzas vivas de nuestra desgraciada patria .... ${ }^{24}$

Aparte los tintes alarmistas de la noticia, lo cierto es que la emigración andaluza a Argentina alcanzó su máximo histórico ese año de 1889. El éxito de la recluta se debió, en gran parte, al carácter subsidiado ("gratuito", se decía) del viaje.

El precio del pasaje en tercera clase a América representaba el mayor desembolso inherente a la emigración. Desde cualquier puerto andaluz para Montevideo o Buenos Aires en 1889, el billete de "tercera corriente" costaba unos 800 reales. ${ }^{25}$ Según el "tipo medio del jornal de los agricultores" en las provincias de Granada, Málaga y Cádiz, ${ }^{26}$ el precio del billete equivalía a 160 días de trabajo (200 días según cálculos de Bernal, que sin embargo no cita las fuentes utilizadas). En todo caso, como indica dicho autor, el cálculo resulta puramente teórico pues, en realidad, un padre de familia jornalero carecía, tenida cuenta de los niveles salariales y los días de trabajo que echaba al año, de cualquier capacidad de ahorro. ${ }^{27}$ Esto reducía la emigración cuando no había pasajes subsidiados, a aquellos que, o bien disponían de pequeñas propiedades que vender e hipotecar, o bien contaban con amigos y parientes en América.

A la altura de 1889, los emigrantes de regiones de amplia trayectoria emigratoria a América podían contar, en mayor proporción, con la ayuda financiera ofrecida por la venta o hipoteca de sus pequeños predios, o por medio de las cadenas migratorias. Así ocurría fundamentalmente con las comunidades de gallegos, asturianos y vascos en Argentina:

"La mayor parte viene a pedido y a costa de las familias y amigos residentes aquí, siendo alojados y mantenidos por los mismos hasta encontrar colocación, lo cual es bastante fácil". ${ }^{28}$

24 “La emigración de los españoles", editorial de La Andalucía, Sevilla, 25 de abril de 1889 , pág. 2.

25 Precio del billete de tercera corriente a Buenos Aires en la "Trasatlántica", publicado en El Defensor de Granada, Granada, 2 de julio de 1889. Se hacían rebajas en el caso de familias de tres o más miembros.

26 Según datos de la Dirección General del Instituto Geográfico y Estadístico (a partir de aquí, IGE), Estadística de emigración e inmigración de España, 1891-1895, Madrid, 1898.

27 VV. AA.: Historia General..., pág. 255. Bernal, A. M.: “ La emigración de...”, pág. 160.

28 "Informe" del cónsul de España en El Tandil, en: Embajada de España, "Informe sobre la emigración española", Buenos Aires, 1891 (manuscrito), AGA, AE, 9067. 
Si bien las cadenas migratorias fueron más extensas y funcionales a principios del siglo XX, la corriente emigratoria gallega, por ejemplo, ya contaba en estas fechas con estos mecanismos de estímulo y ayuda financiera. Esto la hacía relativamente algo más independiente de las políticas de pasajes subsidiados de los gobiernos americanos.

Sin embargo, Andalucía, región de nueva emigración en este período que tratamos, carecía de las necesarias cadenas migratorias establecidas en América para facilitar una emigración proporcional a su población. Ahora bien, y dados los elementos de crisis que actuaron en la década de los 80, existía en 1889 una situación potencialmente emigratoria que fue aprovechada por los agentes de los Señores Acebal Díaz y Cía.. Andalucía presentó ese año su mayor tasa de emigración a América del siglo XIX (7,03 por 1.000), en todo caso inferior a la de las regiones de mayor tradición emigratoria. Algunas provincias andaluzas se destacaron especialmente: Cádiz (16,14 por 1.000) y, sobre todo, Málaga (25,03 por 1.000). Al parecer se destinaron a Málaga unos diez mil de los 30.000 pasajes distribuidos por la "Italo-Argentina". Los malagueños y gaditanos recibieron los pasajes subsidiados por el gobierno argentino "como una bendición" en años de crisis de la vid.

TABla 1. Emigración ANDALUZA A AmÉRICA, 1885-1895

\begin{tabular}{lrrrr} 
Años & América & Argentina & Brasil & Otros \\
\hline 1885 & 853 & 159 & 1 & 693 \\
1886 & 1.024 & 198 & 6 & 820 \\
1887 & 2.717 & 177 & 0 & 2.540 \\
1888 & 2.649 & 1.150 & 328 & 1.171 \\
1889 & 25.368 & 19.750 & 2.057 & 3.561 \\
1890 & 2.480 & 652 & 365 & 1.463 \\
1891 & 3.835 & 211 & 2.465 & 1.159 \\
1892 & 3.386 & 279 & 1.302 & 1.805 \\
1893 & 5.801 & 219 & 3.856 & 1.726 \\
1894 & 4.184 & 351 & 1.703 & 2.130 \\
1895 & 5.501 & 133 & 3.266 & 2.102 \\
\hline TOTALES & 57.798 & 23.279 & 15.349 & 19.170
\end{tabular}

Fuente: Instituto Geográfico y Estadístico (IGE), Estadística de la emigración e inmigración de España, Madrid, 1891 y 1898. 
La emigración andaluza fue bastante dependiente de las políticas de pasajes subsidiados de los gobiernos americanos (Brasil y Argentina) desde 1888-1889. En mayor proporción que en otras regiones españolas, el volumen y destino de la emigración andaluza estuvieron condicionados en parte considerable por los vaivenes de estas políticas.

En el total del período 1885-1895, los andaluces emigraron con preferencia a Argentina, pero cabe hacer una serie de matizaciones cronológicas. En los años 1885-1895, la emigración andaluza a América se dirigió efectivamente en un 62,93\% a Argentina. En 1889 se registra el máximo emigratorio, a causa de la incidencia de los pasajes distribuidos por los Señores Acebal Díaz y Cía., que, por otra parte, no llegaron a alcanzar los 30.000 contratados. Ese año emigraron a Argentina 19.750 andaluces, sin contar los que salieron vía Gibraltar. Sin embargo, la media emigratoria anual a ese país sólo había sido de 421 individuos en los años anteriores (1885-1888) y sería de sólo 257 individuos posteriormente.

En el período 1891-1895, cuando Brasil, y especialmente el Estado de Sao Paulo (desde 1888), potenciaron su política de financiación a la inmigración, la corriente emigratoria andaluza se desvió hacia este destino en un $55,45 \%$. Al ser una emigración subsidiada bastante más sostenida, la media emigratoria anual a Brasil en este último período fue de 2.518 individuos. Mientras tanto, caía considerablemente la emigración a Argentina (5,25\% de la emigración de 1891-1895). En 1890, el Gobierno había dejado de subsidiar la inmigración, a causa de los efectos de la crisis financiera internacional llamada de Baring, sobre una economía tan dependiente del exterior como la argentina. En este contexto hay que enmarcar la decisión de rescindir el contrato con los Señores Acebal Díaz y Cía. a fines del año 1889. ${ }^{29}$ Una decisión que, por otra parte, tampoco fue ajena a las críticas vertidas en algunos periódicos bonaerenses contrarios a la "inmigración artificial", y que cuestionaban entre otros la calidad de los trabajadores andaluces recién llegados. De todas formas, la desproporcionada gran dimensión de la corriente emigratoria de 1889 explica el resultado final favorable a este país en el período 1885-1895.

Estas consideraciones se basan en las estadísticas oficiales españolas, que no registran los embarques clandestinos y por puertos extranje-

29 Como ocurrió con otras líneas creadas para el transporte de ciertas expediciones de emigrantes subsidiadas por gobiernos americanos, la existencia de la "Italo-Argentina" estuvo determinada por la duración del servicio. 
ros..$^{30}$ En Andalucía debemos tener en cuenta la importancia que, a la par que aumenta el flujo emigratorio, adquiere el puerto de Gibraltar. Para conocer el volumen de emigrantes embarcados en el puerto calpense, tenemos que recurrir a las estadísticas argentinas de llegadas con distinción de puertos de procedencia. Sobre estos datos, la tabla siguiente expresa la importancia relativa del puerto de Gibraltar en la emigración a Argentina desde Andalucía en 1889.

TABla 2. INMigración a ARgentina DESDE PUERTOS ANDALUCes (1889)

\begin{tabular}{lcr} 
Puerto procedencia & Inmigrantes & $\%$ \\
\hline Cádiz & 9.643 & 37,60 \\
Gibraltar & 4.567 & 17,80 \\
Málaga & 11.439 & 44,60 \\
\hline TOTALES & 25.649 & 100
\end{tabular}

Fuente: Comisaría General de Inmigración, "Cuadro estadístico del movimiento inmigratorio...1889", Buenos Aires. AGA, AE, 9067.

Según estos datos, el 17,80 del contingente emigratorio embarcado por los puertos andaluces hacia Argentina en 1889 lo hizo vía Gibraltar. Si esta cifra fuese representativa para el caso de los andaluces (suposición razonable dado que éste era, obviamente, el origen regional mayoritario entre los emigrantes salidos por aquellos tres puertos), tendríamos que elevar la cifra de 19.750, registrada por las estadísticas oficiales españolas, a la más real de 23.266 emigrantes. Esta última cifra se acerca más a los 24.000 emigrantes españoles que, de acuerdo con algunos cálculos de la época, tenía previsto transportar la "Italo-Argentina".

\section{Componente familiar}

Los segmentos poblacionales más móviles son los que se encuentran en los veinte y los treinta años de edad. A su vez, en sociedades tradicio-

30 Estas salidas no registradas por el Instituto Geográfico y Estadístico suponen una infravaloración oficial del éxodo español . Sánchez Alonso, B.: Las causas de la emigración española. 1880 1930, Madrid, 1995, pág. 109. La autora considera que las discrepancias entre las series estadísticas española y americanas se explican por: la emigración clandestina, la efectuada por puertos extranjeros y, sobre todo, por los diferentes criterios de compilación. 
nales los hombres eran más móviles que las mujeres. No es extraño que el perfil clásico del emigrante europeo y español fuera el de un varón joven soltero, con un destino fundamentalmente urbano en América. Ahora bien, entre los andaluces reclutados para Argentina se da un alto componente de familias que parecían romper todos los lazos con la tierra de origen. Esto explica especialmente la alarma despertada en la opinión pública española y andaluza:

"Y no es que emigran sólo los individuos con la esperanza de regresar a la tierra que los vio nacer, con más o menos ahorros, no, es que también emigran las familias enteras, las que jamás retornarán a la patria y que vivirán y morirán bajo una nueva nacionalidad'. 31

La política de pasajes subsidiados se dirigió de hecho a la recluta de familias agricultoras. Éstas garantizaban un poblamiento más estable de las nuevas colonias agrícolas que se estaban fundando en Argentina. Se habla de fuerte participación familiar en la emigración al registrarse una alta proporción de mujeres y niños. Así pues, uno de los indicadores clásicos de este carácter familiar son las tasas de masculinidad:

TABLA 3. ÍNDICES DE MASCULINIDAD DE LA EMIGRACIÓN ANDALUZA A ARGENTINA Y BRASIL, 1885-1895

\begin{tabular}{lcr} 
Años & Argentina & Brasil \\
\hline 1885 & 231 & 0 \\
1886 & 175 & 500 \\
1887 & 234 & 0 \\
1888 & 161 & 123 \\
1889 & 116 & 112 \\
1890 & 153 & 130 \\
1891 & 167 & 137 \\
1892 & 121 & 111 \\
1893 & 204 & 112 \\
1894 & 195 & 110 \\
1895 & 151 & 111 \\
\hline TOTALES & 1.908 & 1.446
\end{tabular}
y 1898.

Fuente: Instituto Geográfico y Estadístico (IGE). Estadística de la emigración... Madrid, 1891

31 "La emigración de los españoles", editorial citado de La Andalucía. 
En el caso de emigración a Argentina, sólo en 1889 las mujeres andaluzas participaron casi en igual medida que los hombres (116 hombres por cada 100 mujeres). Esta participación se desequilibró de nuevo tras cerrarse en 1890 la política de financiación a la inmigración del Estado argentino, a causa de la citada crisis de Baring. Por otro lado, Brasil atrajo en una más equitativa proporción a hombres y a mujeres andaluces, al sostenerse más regularmente desde 1888 los pasajes subsidiados por el Estado de Sao Paulo. La emigración a Brasil, en tanto que fundamentalmente subsidiada, fue una emigración de familias.

Eran en su mayoría familias agricultoras..$^{32}$ No resulta extraño teniendo en cuenta la ocupación para la que eran reclutadas y el hecho de que Andalucía, como España en su conjunto, era una sociedad básicamente agraria a fines del siglo XIX. El vicecónsul de España en Mendoza, provincia donde llegaban principalmente los andaluces, dijo que en su distrito:

"La mayoría de los españoles son agricultores, alcansando [sic] éstos sobre los industriales una proporción relativa de un ochenta por ciento. El resto, de veinte, queda reservado a los albañiles, carpinteros, herreros, sirvientes, dependientes de comercio". ${ }^{33}$

En suma, la emigración andaluza a Argentina a fines del siglo XIX fue mayoritariamente subvencionada y familiar. Así lo reconocía en 1890 el cónsul general de España en Argentina:

\begin{abstract}
"Al amparo del gobierno argentino casi puede asegurarse que únicamente han venido los emigrantes de las provincias andaluzas donde sin duda, y tal vez porque un español de aquellas regiones entendió en el asunto, hicieron sus levas los agentes oficiales de inmigración. Llegaron, entonces, innumerables familias andaluzas contratadas para la fundación de colonias vinícolas, pero no hay noticia de que haya prosperado ni una sola de estas empresas[...] Por regla general, los emigrantes llegan espontáneamente [sic] y en su mayoría aportando recursos con que atender a sus primeras necesidades durante algunos días". ${ }^{34}$
\end{abstract}

Los 30.000 pasajes "subsidiarios" fueron anunciados en ocasiones como "pasajes gratuitos". En realidad, el Estado argentino no los consideraba como una inversión a fondo perdido, sino como adelanto del billete. Cada emigrante beneficiado por uno de estos pasajes tenía que firmar, a su

32 Mateo Avilés, B.: La emigración andaluza...

33 Embajada de España, "Informe....".

34 Ibídem. 
llegada a Buenos Aires, letras por el importe del mismo (60 pesos). Estas letras suponían un interés del $10 \%$ anual y una amortización del principal del $20 \%$ cada semestre. En total, y si se cumplían estos plazos, el emigrante estaba obligado a reembolsar los 60 pesos de pasaje, más un interés de 15 pesos, en dos años y medio. A pesar de suponer una considerable rebaja respecto al precio de los pasajes no subvencionados, el vicecónsul español en Mendoza reconocería que:

"El valor del pasaje, según la Ley, debe ser reembolsado por el beneficiado en condiciones fáciles, lo cual no es probable cumplan por imposibilidad material unos y por mala fe otros". ${ }^{35}$

\section{Los andaluces en Argentina en 1890}

\section{Llegada a Buenos Aires}

El Hotel de Inmigrantes de Buenos Aires, albergue creado para acogerlos en los primeros días, fue el destino inicial de muchos europeos llegados al Plata. No poseyendo contactos en Argentina que les pudiesen introducir en el nuevo país, este Hotel fue probablemente lugar de paso para muchos andaluces. Alabados y denostados a causa de las condiciones de habitabilidad, los Hoteles proporcionaban alojamiento y manutención gratuitos a costa de la Comisión de Inmigración. Al cabo de los tres primeros días estipulados por ley, los inmigrantes salían para dirigirse al punto asignado por la Oficina de Trabajo (esto es, una oficina de colocación).

$\mathrm{Al}$ parecer, los inmigrantes no estaban obligados a aceptar este primer contrato. Pero en la mayoría de los casos era la única manera de incorporarse al mercado de trabajo en un país desconocido y donde se carecía de contactos personales. Aceptada la oferta de trabajo, los inmigrantes eran transportados a cargo de la Comisión de Inmigración por ferrocarril, en barcos río arriba y/o en carros a las localidades donde residirían, un "viaje penoso y con alimentación escasa" según el cónsul en La Rioja.

"La oficina de trabajo les proporcionaba la colocación; pero no son contratos obligatorios, sino libremente [sic], internándolos por cuenta del Gobierno a los puntos que eran solicitados o que los mismos inmigrantes indicaran. Al solicitar una empresa o un particular de la Oficina de Inmigración o de las comisiones que hay establecidas

35 Ibídem. 
en diversos puntos de la República los obreros o peones que necesitaba, establecían previamente las bases y condiciones de precio y trabajo; viéndose obligada la empresa o el particular al fiel cumplimiento de lo pactado por las leyes especiales que rigen al respecto y que la Oficina de Inmigración o Comisiones mencionadas hacen cumplir, en casos precisos, por intermedio de los juzgados". ${ }^{36}$

\section{Distribución geográfica de los españoles}

La distribución de la inmigración en Argentina fue muy desigual, determinando fuertes desequilibrios urbanos posteriores. El litoral o zona pampeana pasó de contar con un $30 \%$ de la población a un $64 \%$, entre 1850 y 1914, mientras que el centro y noroeste (Córdoba, Tucumán, La Rioja, etc.), que habían contado con más de la mitad de la población en la época colonial, retrocedieron hasta poseer sólo un $22 \%$ del total de 8 millones en 1914. Las provincias de Buenos Aires, Santa Fe, Entre Ríos y la Pampa, así como el sudeste de Córdoba, recibieron el mayor número de inmigrantes europeos, mientras que en la región de Cuyo, sólo Mendoza gracias al desarrollo de la industria vinícola - sobresale en cuanto a recepción de inmigrantes. En el noroeste, Tucumán recibió el mayor caudal migratorio debido a la expansión de la industria azucarera. ${ }^{37}$

La distribución de inmigrantes refleja en parte las oportunidades económicas que ofrecía el país, pero la concentración de población en Buenos Aires y, sobre todo, en la Capital Federal, produjo un claro desequilibrio demográfico. De los casi 664.000 habitantes con que contaba la ciudad en 1895, más de la mitad eran extranjeros, y de éstos, poco más de ochenta mil eran españoles (24\%), frente a más de ciento ochenta mil italianos (53\%). Ese desequilibrio fue en aumento debido al efecto acumulativo que generaron las cadenas migratorias, especialmente funcionales en las primeras décadas del siglo XX.

Desde un principio, la Comisión de Inmigración argentina intentó orientar a los inmigrantes hacia regiones menos favorecidas por la corriente inmigratoria llamada "libre". Esta labor de orientación sólo era efectiva con los inmigrantes que habían llegado con pasajes subsidiados por la Comisión. La Oficina de Trabajo se encargó de enviarlos allí donde eran demandados como mano de obra. Aunque algunos andaluces se quedaron

36 Embajada de España en Argentina, "Informe...".

37 Sánchez Alonso, B.: La inmigración española en Argentina. Siglos XIX y XX, Oviedo, 1992, págs. 66-67.

Tomo LIII, 2, 1996 
como "jornaleros" (esto es, mano de obra no cualificada) en el ámbito urbano de Buenos Aires ${ }^{38}$ otros decidieron aceptar las ofertas de empleo en provincias.

\section{Los andaluces en la geografía argentina}

Como evidencia cualitativa, los informes consulares españoles son significativos al respecto. Por real orden de 11 de julio de 1891, el Ministerio de Estado encargaba a los Consulados Generales españoles la elaboración de un completo informe sobre la emigración española en los países americanos. En estos informes los agentes consulares debían responder a 31 preguntas, agrupadas en estos epígrafes: a) Datos generales, b) Carácter de la emigración, c) Posición de los emigrantes, d) Vida de los emigrantes, e) Reunión de los emigrantes. Esta es la estructura que sigue el "Informe sobre la emigración española a la República Argentina", compuesto de los informes de 15 agentes consulares españoles distribuidos por la geografía provincial de Argentina (no aparece el informe correspondiente a Buenos Aires), y de un resumen a cargo del cónsul de España.

Según éste último, la inmigración española en Argentina había adquirido "proporciones realmente colosales" en los años inmediatamente anteriores a 1891. Los distintos componentes regionales de esta inmigración tuvieron pautas diferenciadas en cuanto a su distribución en territorio argentino. Los nuevos grupos de gallegos destacaban en la generalidad de los distritos consulares, excepto en Mendoza. Aquí, como indica el agente consular español, los andaluces constituían el grupo regional más importante de los llegados en 1889.

"[Proceden] principalmente del reino de Andalucía, y muy particularmente de Málaga, Cádiz y Granada. No ha entrado ningún vascongado”.

Aunque con menor peso relativo, según las mismas fuentes, también se observó una afluencia destacable de andaluces en Tucumán, La Rioja, San Nicolás y Rosario de Santa Fe. La mayoría de los 15 agentes consulares constataron un hecho: lo novedoso de la inmigración andaluza en sus distritos. Así lo refiere el cónsul en Rosario:

38 Sánchez Alonso, B: La inmigración española..., pág. 114. A este respecto, se ha dicho que las migraciones transoceánicas tuvieron un fuerte componente de emigración campo-ciudad. 
"El número de estos últimos [los andaluces] antes de 1889 era insignificante, y ahora es crecidísimo, en su mayoría de las provincias de Málaga y Cádiz". ${ }^{39}$

En Bahía Blanca, donde la presencia gallega y vasca era tradicional, la novedad la constituían también los andaluces:

"Hasta el año 1888, si bien concurrieron españoles de diversas provincias, eran la mayor parte de los aquí residentes originarios de las provincias vascongadas y de Galicia. Desde aquella fecha se ha hecho notable por su número la emigración andaluza".

Algunos no encontraron ocupación arreglada a sus aptitudes o a sus expectativas. Otros prefirieron aceptar los trabajos disponibles, en espera de una mejor oportunidad y radicarse en el lugar. Así lo indica el vicecónsul español en Dolores:

"Ignoro [...] de qué provincia proceden, si bien pudiera afirmar que en los últimos tiempos han superado en número los de las provincias andaluzas, muchos de los cuales han tomado diversos rumbos, habiéndose radicado algunos con sus familias en este partido, ya como agricultores, ya entrando en la Policía como agentes de seguridad, por no permitirle su falta de recursos esperar a que se les proporcionase algún quehacer arreglado a sus aptitudes".

TABLA 4. DistRIBUCiÓN GEOGRÁFICA DE LA POBLACIÓN ESPAÑOLA EN ARgEnTINA, 1869 y 1895 (en \%)

\begin{tabular}{lrr} 
& 1869 & 1895 \\
\hline Capital Federal & 41,8 & 40,4 \\
Buenos Aires & 42,2 & 35,2 \\
Santa Fe & 4,6 & 10,6 \\
Entre Ríos & 8,9 & 3,2 \\
Córdoba & 0,7 & 2,7 \\
Mendoza & 0,2 & 1,4 \\
San Juan & 0,1 & 0,9 \\
Tucumán & 0,1 & 2,0
\end{tabular}

Fuente: Sánchez Alonso, La inmigración española ..., pág. 68.

39 A partir de aquí, las citas de origen consular proceden del informe ya citado de la Embajada de España en Argentina. 
Tras 1889, la distribución geográfica de los españoles en Argentina no cambió esencialmente respecto a la existente en 1869. Más del $40 \%$ de ellos residía en la capital federal, según el siguiente censo de 1895. Ahora bien, hubo un apreciable incremento de la participación de los españoles residentes en las provincias de Santa Fe, Córdoba, Mendoza y Tucumán.

\section{La incorporación al mercado laboral en tiempo de crisis}

\section{Los contratos}

La aparición del ferrocarril a mediados de la década de los ochenta en la región cuyana, la principal productora nacional de vinos, incentivó la ampliación de la superficie de viña al disminuir el costo del producto colocado en el litoral. ${ }^{40}$ También facilitó el transporte de la mano de obra necesaria para aumentar la producción. Una vez en Mendoza, las familias inmigrantes pudieron seguir otros diez días bajo el auxilio de la Comisión de Inmigración:

"Este plazo es prudencial, teniendo en cuenta que es tiempo sobrado para que encuentre colocación un buen trabajador".

Esto era así en épocas "normales", cuando no arreciaban las crisis coyunturales propias de un período de rápido crecimiento. Tampoco parecía haber problema para encontrar trabajo como jornalero en los ingenios azucareros de Tucumán, según el parecer del cónsul en esa provincia:

"Los emigrantes que llegan al litoral con pasajes subsidiados, o adelantados por el gobierno argentino, se trasladan por cuenta del mismo y por medio de los ferrocarriles a esta provincia, donde existe un Hotel que los alberga durante tres días, si no hay pedidos de operarios por los industriales, pero generalmente siendo más los pedidos que los inmigrantes, en cuanto se refieren a agricultores y jornaleros".

Los productores de vinos de Mendoza contrataban a los trabajadores por familias o grupos para las labores de plantación de viñas (así pues, los niños a partir de cierta edad tenían que trabajar, como también ocurría en Andalucía). Las condiciones de estos contratos eran las siguientes:

40 Fernández, A.: “Emigración y 'mercado étnico'. Las exportaciones a la Argentina entre 1880 y 1930", ponencia presentada en el IV Encuentro de Americanistas, Oviedo, 1994, pág. 3 (copia de la ponencia). 
"Las familias suelen efectuarlos [los contratos], así como aquellos otros que permane-
cen unidos, pudiendo por consiguiente cumplir su compromiso. Versan generalmente
sobre plantación de viñas, y las ventajas para el trabajador estriban sobre el precio
asignado a cada planta, una vez arraigada, que no suele bajar de 11 hasta 15 centavos,
proporcionándole el dueño del suelo animales de labor, herramientas, semillas, antici-
po de dinero, para descontar al término del contrato, del saldo que deban recibir. Estos
contratos tienen una duración que no baja de tres años ni escede [sic] de cinco, siéndo-
les permitido durante este tiempo hacer siembras determinadas por su cuenta o a
medias, con cuyo producto satisfacer las necesidades más perentorias de la vida".

Todo comienzo era difícil, y en el caso de las familias andaluzas pudo serlo en mayor medida que para los inmigrantes que contaban con amigos y parientes establecidos en ámbitos urbanos. El contrato de tres años funcionaba de hecho como una garantía para que las comisiones provinciales de inmigración hiciesen cumplir los débitos adquiridos por el inmigrante con el Estado argentino. En fin, no se trataba sólo de arreglárselas para subsistir. Había que pagar las letras por el pasaje subsidiado, una obligación que - recordemos - no se llegó a cumplir por la mayoría.

Por otra parte, arraigasen o no todas las cepas, al final de tres o cinco años la familia también vería descontados de sus eventuales ganancias los anticipos hechos por el propietario. En el caso de no poder reembolsar estos adelantos, los intereses se acumularían y se haría aún más difícil el ahorro en una economía precaria.

En Tucumán, donde la recolección de la caña requería otros marcos contractuales, los trabajadores inmigrantes se arreglaban con los patronos por medio de unas libretas llamadas de "conchavo"; estos papeles se registraban en las oficinas de policía. Pero también había otros tipos de contratos para el arrendamiento de terrenos (lo corriente era la aparcería) y en el sector de la construcción.

Mejor comunicada que Tucumán, Rosario era la capital de una provincia "rica y floreciente", ${ }^{41}$ Santa Fe. No sólo recibía inmigrantes sino que también servía, como Mendoza, de punto de redistribución de los mismos por el interior. Rosario contaba con el segundo Hotel de Inmigrantes de los creados en la República, al ser su provincia la más favorecida por la creación de nuevas colonias.

Insignificante el número de andaluces antes de 1889, desde entonces también fue "crecidísimo" en esta provincia. Acceder a la propiedad de una de las parcelas de las numerosas colonias requería contar con ciertos aho-

41 Cónsul de España en Rosario. 
rros para hacer frente a los primeros pagos. Las condiciones de compra se especificaban en un "boleto de compra-venta" proporcionado por el Banco Colonizador Nacional, que disponía de agencia en las colonias de su titularidad. Se pagaba un $10 \%$ del valor del terreno al contado y lo demás en tres plazos a convenir, con un interés anual del $8 \%$. En el caso de la colonia "Esperanza", cada concesión tenía una superficie de 30 a 33 hectáreas, y el valor de venta oscilaba entre 600 y 800 pesos moneda nacional. En ocasiones se ofrecía al colono los primeros medios materiales para la puesta en explotación del terreno. Con un trazado hipodámico, las colonias solían contar con un núcleo poblacional que contenía los servicios públicos, entre ellos, el imprescindible apeadero ferroviario. Ni que decir tiene que la propiedad de la tierra estuvo en principio fuera del alcance de la mayoría de los andaluces, que en muchas ocasiones carecían de los más mínimos recursos.

\section{El trabajo a jornal}

Además de la compra de un terreno o el contrato con un propietario, el trabajo a jornal era otra modalidad de incorporación al mercado laboral. En las provincias con significativa presencia andaluza los jornales oscilaban entre 1 peso/día y 3 pesos/día.

\section{TABla 5. SALARIOS AgRícolas EN LAS PROVINCIAS DE MAYOR INMIGRACIÓN ANDALUZA (1891) (EN PESOS)}

\begin{tabular}{lcc} 
Provincia & Salario Mínimo & Salario Máximo \\
\hline Sta. Fe & $1,5 /$ día & 3/día \\
Mendoza & $1,2 /$ día & $2 /$ día \\
S. Nicolás & $1 /$ día & 3/día \\
Tucumán & $20 /$ mes + comida & $30 /$ mes + comida
\end{tabular}

Fuente: Embajada de España en Argentina, "Informe ..."

Los salarios estaban en función de las aptitudes, la época del año y la categoría profesional (bracero, capataz). En Santa Fe un simple bracero podía ganar hasta tres pesos al día, siempre que fuera "muy aventajado en 
su oficio". Pero la "inmensa mayoría" no pasaba de dos pesos diarios. En Mendoza el jornalero podía conseguir hasta 2 pesos "según la época". En Tucumán parte de la retribución de los trabajadores de la caña se hacía en comida. La media de los jornales agrícolas en Santa Fe, Mendoza y San Nicolás oscilaba entre 1,23 pesos como mínimo y 2,67 pesos como máximo (son jornales muy inferiores a los ganados en la provincia de Paraná por los peones agricultores vascos y gallegos: 4-5 pesos/día).

Según el cambio corriente en 1891, el jornal de 1,23 pesos papel moneda nacional argentina equivalía aproximadamente a 1,5 pesetas españolas. El tipo medio del jornal de los agricultores en las provincias andaluzas de mayor emigración a Argentina variaba:

TABla 6. JoRnal AGRARIo en ANDAluCía, 1893 (PESETAS/DÍA)

\begin{tabular}{lc} 
Provincia & Jornal \\
\hline Cádiz & 1,42 \\
Málaga & 1,37 \\
Granada & 1,25
\end{tabular}

Fuente: IGE, Estadística..., 1898.

Aun tratándose de tipos medios de jornal, en las tres provincias andaluzas eran inferiores a la media de los jornales mínimos de los braceros en Argentina. Pero para una mejor comprensión de las condiciones de vida de la familia jornalera en Argentina, debemos tener en cuenta otras consideraciones, como la capacidad real de consumo.

La depresión económica de los primeros años noventa en Argentina era el momento menos propicio para empezar una nueva vida en país extranjero. El jornal se pagaba en pesos papel, con el riesgo casi cierto de una rápida devaluación. Mientras tanto, los precios de artículos de consumo seguían las oscilaciones del oro, según el vicecónsul en Mendoza. Así que eran pocos los que podían ahorrar siendo trabajadores dependientes. Aquellos afortunados que conseguían un jornal se limitaban a subsistir esperando épocas mejores, pues la carestía de los artículos de primera necesidad absorbía los jornales. El nivel de vida de los jornaleros, especialmente españoles, fue descrito en estos términos por el cónsul de España en Rosario: 


\begin{abstract}
"Supongamos que todos nuestros trabajadores ganan dos pesos diarios: de esos dos pesos tienen que comprar pan, que cuesta 30 centavos el kilo; carne, que cuesta 20 centavos el kilo (éste es su principal alimento y el más barato); judía, que cuesta 30 o 40 centavos el kilo; patatas, que cuesta 20 centavos el kilo; aceite, que cuesta $\$ 1,50$ el kilo (grasa consumen muy poca nuestros trabajadores); carbón, que cuesta un peso la arroba; infinidad de aguas venenosas a las que se da el nombre de vino, y que cuesta de 50 a 60 centavos el litro (lo que se llama vino, son muy pocas las personas que por esta tierra lo beben en la época presente); habitación, que no les ha de bajar de 7 a 8 pesos mensuales, etc. Calcúlese, además, lo que les ha de costar la reposición, conservación y limpieza de la ropa; algún vicio inocente, pero caro, como el fumar, y considere V.E. lo que pueden ahorrar nuestros braceros: nada o bien poco más. Todo esto, como llevo dicho, calculando que ganan 60 pesos mensuales, que no es así; pues en su mayor parte, me atrevo a decir que no ganan más de 45 ”.
\end{abstract}

La situación era más difícil para aquellos que no contaban con pequeños ahorros traídos de España, o con amigos y parientes en Argentina que les pudiesen proporcionar trabajo en un comercio o en el campo. En época de crisis, un problema elemental es siempre encontrar trabajo. Llevar mujer, hijos pequeños y, a veces, los abuelos, no sólo hacía más dramática la situación, sino que además podía significar una desventaja:

"Hay una infinidad de ellos que están sin trabajo, pasando toda suerte de privaciones, buscando en vano en qué ocuparse para salir de su mísera situación. Este invierno han sido muchos los que han tenido que mal vender todas sus ropas para atender a su sustento. Y menos mal que esto ocurriera al trabajador soltero, pues éste, libre de toda traba, puede trasladarse con toda facilidad de un punto a otro de la República en busca de trabajo; pero no sé cómo se las puede componer el trabajador casado y con hijos, que llega a verse falto de los medios indispensables para la vida" (vicecónsul en Rosario de Santa Fe).

Por su parte, el vicecónsul en Mendoza achacaba la situación de miseria en que vivían especialmente los jornaleros andaluces a su dudosa capacidad como trabajadores:

"El trabajador sufre en los días de crisis por el retraimiento del capital, y mucho más si su capacidad productiva es pequeña como acontece a muchos de los emigrantes españoles, particularmente los de las provincias del mediodía".

Lo cierto es que la crisis de los noventa, a pesar de su carácter general, afectó más crudamente a las familias jornaleras, o sea, a la mayoría de los emigrantes andaluces.

"Hoy, a causa de la crisis financiera por que atraviesa el país, el obrero y jornalero sufren privaciones por la escasez de trabajo y carestía de los artículos de primera 
necesidad. Este malestar se nota especialmente en la emigración andaluza que ha llegado al país en número considerable los años 1888-89-90 y 91 . Son en general familias con numerosa prole, han venido sin recursos de ninguna clase, alucinados por las promesas y engaños de agentes sin escrúpulos ni conciencia, y hoy se encuentran en condiciones verdaderamente lamentables. Diariamente llegan a este Viceconsulado en demanda de auxilio o socorro pecuniario que me es imposible atender a todos en la plenitud de su pedido por razones fáciles de comprender. En los cuatro años indicados han entrado en la localidad por intermedio de la Oficina de Inmigración 1.436 emigrantes entrando en ese número 433 niños de 12 años abajo, siendo la inmensa mayoría, o todos casi, procedentes de las regiones andaluzas. Son estos los que más sufren, como he dicho, las consecuencias del malestar actual" (vicecónsul en Bahía Blanca).

$\mathrm{Ni}$ que decir tiene que la capacidad de ahorro de un jornalero en esta situación era mínima, por no decir nula. Esto parece que imposibilitó el establecimiento de redes de estímulo y ayuda financiera a la emigración con las localidades gaditanas, malagueñas y granadinas de origen. Sin descontar otros posibles factores coadyuvantes, esta situación de relativa desventaja explica que no se diera, con intensidad similar a la de otras regiones españolas, un flujo migratorio sostenido entre Andalucía y Argentina en la década siguiente a 1889 . 